\title{
Thermovision and spectroradiometry in stand-off detection of chemical contamination
}

\section{Zastosowanie termowizji i spektroradiometrii do zdalnego wykrywania skażeń chemicznych}

*The Institute of Environmental Protection - National Research Institute, 5/11d Krucza Street, 00-548 Warsaw email: marek.chmiel@ios.edu.pl, dariusz.calus@ios.edu.pl,krystian.szczepanski@ios.edu.pl.
**Military University of Technology, Institute of Optoelectronics, 2 Gen. Sylwestra Kaliskiego Street, 00-908 Warsaw, email: mkastek@wat.edu.pl.

Keywords: passive detection of gases, remote sensing, multispectral detection

Słowa kluczowe: pasywna detekcja gazów, spektroradiometria, wielowidmowa detekcja

\section{Abstract}

The range of applications in which remote detection of chemical compounds is used extends from monitoring of technological processes through diagnostics of industrial installation and environmental control up to military applications. The methods and the devices used for the passive detection of selected gases are presented. The change in the signal reaching the camera caused by the presence of gas was calculated. The successful detection can be achieved if the absorption (or emission) of a gas cloud, located between object (background) and the camera, causes signal change greater or equal to noise equivalent temperature difference (NETD) of the camera.

๑) IOŚ-PIB

\section{INTRODUCTION}

Pollution of the natural environment is mainly caused by the development of industries and agricultural activity, energy production and municipal waste. Environmental pollution is considered to be the presence of any substance not being its natural component. Polluting substances are mainly gases and liquids (in the form of aerosols) and solids (in the form of dust). Pollution of the environment may affect soils, water, air or living organisms.

Pollution may originate from natural and anthropogenic sources. Natural sources of carbon oxides are respiration processes of living organisms, as well as volcanoes, geysers, marshes, forest fires, soils and rocks affected by erosion. Organic dust particles reach the atmosphere from green terrains in the form of, for example, pollen grains.

Human activity leads to the formation of pollution in amounts that exceed the ability of the natural environment to use them. This results in the imbalance of the equilibrium in the biosphere, causing effects that are not always foreseeable.

The first step in environmental protection is to identify and determine the type of pollution and its scale by monitoring the state of the environment. Monitoring threats to environmental security may be conducted in a stationary network or in movable monitoring points. In the second case, the measuring apparatus

\section{Streszczenie}

Zagadnienie zdalnej detekcji substancji chemicznych występuje w wielu, często krańcowo odległych, dziedzinach działalności ludzkiej. Spektrum zastosowań tego typu urządzeń rozciąga się od monitorowania procesów technologicznych poprzez diagnostykę instalacji przemysłowych i monitoring środowiska naturalnego po zastosowania militarne. W artykule zostały przedstawione różne metody i urządzenia do zdalnej, pasywnej detekcji skażeń chemicznych. W części teoretycznej przedstawiono analizę możliwości detekcji skażeń chemicznych przez kamerę termowizyjna. may be installed in a car, a balloon, a parachute, a helicopter, an airplane, an unmanned aerial vehicle (UAV) or other unmanned vehicles. Methods used for chemical, biological, radiological, nuclear and explosives threat detection can be basically divided into two groups according to the method of taking samples for analysis.

Collection of samples at the sites may be dangerous for the person performing measurements, and the sample may not always come from the right place. Methods of remote detection, identification and measurement of concentration of the harmful substance are devoid of these disadvantages and enable the monitoring of the environment at a distance of many kilometres depending on the measurement technique used.

In remote detection, optoelectronic techniques and methods play an important role. They are a very precise tool for the detection and identification of concentrations of gaseous atmospheric pollutants and are becoming commonly used to complement the presently used methods of monitoring the environment.

One of the more important advantages of optoelectronic methods is full automation of measurement, clear results, possibility to take measurements without taking samples as well as the integration of different optoelectronic systems in the process of acquiring, processing and transmitting data. 
The two types of remote monitoring are stand-off type and remote type. The stand-off (optoelectronic sensors and radars) enables the detection of pollutant (gases, aerosols, fumes and dust) from a considerable distance without any contact with the contaminated area.

These are active laser systems (lidars with tuneable lasers and data processing systems enabling the determination of difference absorption - difference absorption lidar [DIAL]) or passive thermovision systems with narrow filters adjusted to gas absorption bands and showing changes in the transmission of radiation absorbed along the path of gas occurrence [Lavoie et al. 2007].

A single stand-off station may observe a large area, the size of which depends on the range, field of vision and speed of scanning.

The development of devices that are able to detect aerosols of chemical compounds was brought about by advancements in matrix infrared detectors. Devices equipped with modern highsensitivity infrared detectors enable the detection of chemical compounds from a distance of 1-2 km.

Research on the construction of such devices has been conducted in research centres all over the world since the 1980s. Infrared devices for the detection of chemical substances (gases) in the atmosphere must have an appropriate temperature and spectral resolution. Two main types of devices are distinguished. One of the solutions is a system similar to a thermovision camera additionally equipped with a system of filters guaranteeing the desired spectral resolution and signal analysis systems. The second solution is a device with infrared spectral radiometers [Kastek et all 2008].

An analysis of modern passive stand-off systems operating inclose, medium and distant infrared ranges is presented in the article. The theoretical part includes an analysis of the possibilities of detection of chemical contamination by an imaging Fouriertransform spectrometer (IFTS). The results of IFTS polygon tests obtained during the detection of various chemical substances are also presented.

\section{THEORETICAL FUNDAMENTALS OF GAS DETECTION}

Thermovision cameras equipped with appropriate sets of filters and special software, as well as infrared spectrometers, make it possible to obtain a thermal image of the observed scenery in which the areas where chemical vapours occur are highlighted. Detection of gases is possible due to the fact that a large number of chemical substances, ranging from molecular pairs to aerosols, have absorption or emission bands in the infrared spectral range. The most commonly analysed absorption bands with the ranges $3-5$ and $8-12 \mu \mathrm{m}$, in which thermovision devices and spectroradiometers usually operate in, because of the good transmission of the atmosphere.

The detection of gases involves the comparison of two thermal images. The first image is obtained from the radiation reaching the lens of the device for which the spectral range is the same as the spectral absorption or emission of infrared radiation of the chemical compound to be detected. The second image, the socalled reference image, is obtained from the radiation reaching the device operating beyond the spectral range of radiation absorption by the gas.
In order to detect the gas plume, it is essential to begin with an underlying physics-based model for the hyperspectral data. This allows us to mathematically describe the radiance, defined as the flux per unit projected area per unit solid angle, incident at the sensor. This at-sensor radiance is a summation of the contributions of numerous terms including both reflected solar and emitted thermal effects. In the long-wavelength infrared [LWIR] spectrum, emissive terms dominate and reflective effects are generally considered negligible.

In the measurement situation when the sensor collect the radiation from the emission of the background throw the atmosphere without the gas plume, the entire power reaching the detector may be expressed as

$P_{O D N}=q\left[M\left(T_{b}\right) \tau_{a}+M\left(T_{a}\right)\left(1-\tau_{a}\right)\right]$,

where

$M(T)$ is the density of exitance of an object having a temperature $T$,

$T_{b}$ is the temperature of the background,

$T_{a}$ is the temperature of the atmosphere,

$\tau_{a}$ is the atmospheric transmission coefficient,

$q$ is the construction constant of the device.

The exitance of the object found within the field of vision of the detector is expressed as

$$
M(T)=\int_{\lambda_{1}}^{\lambda_{2}} \frac{c_{1}}{\lambda^{5} \cdot\left(e^{\frac{c_{2}}{\lambda \cdot T}}-1\right)} d \lambda,
$$

where

$\lambda_{1} \div \lambda_{2}$ is the wavelength limits (field of vision range of the thermovision camera),

$c_{1}$ and $c_{2}$ are Planck's constant.

The construction constant of the camera can be expressed as

$q=\left(D_{o p t} \cdot \operatorname{tg} \frac{\mathrm{IFOV}}{2}\right)^{2}$

where

$D_{\text {opt }}$ is the average diameter of the gateway aperture of the camera lens,

IFOV is the angle of view of an individual detector in a focal plane array/detector array.

If a cloud of gas appears in the pathway of the object (the background) and the thermovision camera (Fig. 1) and the absorption bands of the gas are within the vision range of the camera, then the power of radiation reaching the detector alters according to the following equation:

$P_{G A Z}=q\left\{M\left(T_{b}\right) \tau_{a, 1} \tau_{a, 2} \tau_{m}+M\left(T_{a}\right)\left[\tau_{m} \tau_{a, 2}\left(1-\tau_{a, 1}\right)-\tau_{a, 2}+1\right]+M\left(T_{m}\right)\left(1-\tau_{m}\right) \tau_{a, 2}\right\}$

\section{where}

$T_{m}$ is the temperature of the gas

$\tau_{a, 1}$ is the spectral atmospheric transmission coefficient for the atmosphere found between the background and the gas cloud,

$\tau_{a, 2}$ is the spectral atmospheric transmission coefficient for the 


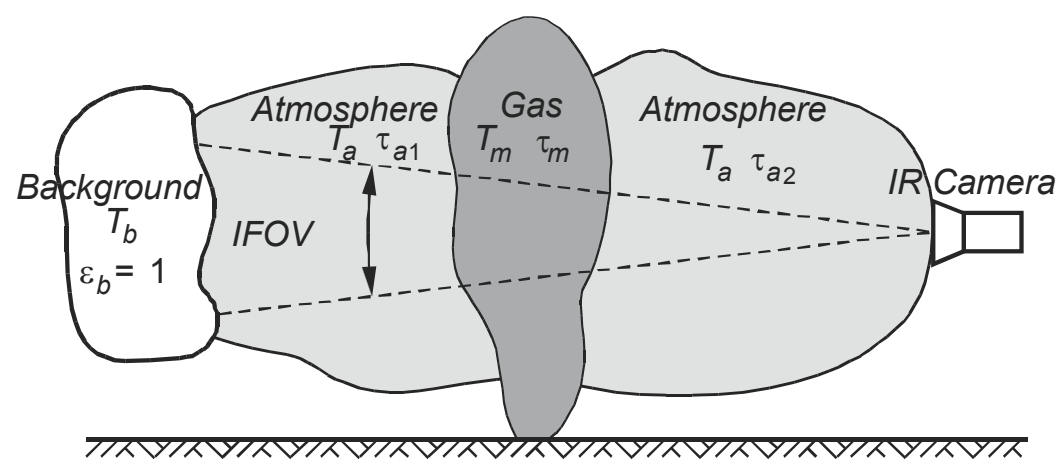

Figure 1. The measurement situation and the adopted marking for the analysis of gas in the atmosphere.

atmosphere found between the gas cloud and the thermovision camera,

$\tau_{m}$ is the spectral gas transmission coefficient.

The gas will be detected only when the difference in signals (in the presence or absence of gas) is at least equal to the noise equivalent temperature difference (NETD):

$\left|P_{O D N}-P_{G A Z}\right| \geq P_{N E T D}>0$,

\section{where}

$P_{\text {NETD }}$ is the radiant power resulting from the NETD of the device, Leaving aside the impact of emissions from gas, the atmosphere or background, it may be assumed that when the temperature of the gas does not differ from the temperature of the atmosphere and the temperature of the background (object), gas detection is not possible even in the case of its high concentration. This statement may be proved by substituting dependency (5) with dependency (1) and (4), and assuming that $T_{m}=T_{a}=T_{b}=T$. We then get an equation from which it is clear that the power of radiation reaching the infrared detector in both the absence and presence of gas is identical.

$$
\left|P_{O D N}-P_{G A Z}\right|=0
$$

In a situation where the gas temperature is different from the atmosphere and background temperatures, for respective NETD of the device, the effective detection of the gas will depend on its concentration because bands of absorption alter with the change in gas concentration. Figure 2 depicts the absorption bands for methane (in wavelength functions) for two different concentrations.

Awareness of the methane absorption bands for different concentration values enabled the determination of the required difference in temperature between the background (object) and the gas in the NETD function of the thermovision camera (Fig. 3). Assuming that the NETD of the camera to be $0.2 \mathrm{~K}$, the required temperature difference between the object $\left(T_{b}=293 \mathrm{~K}\right)$ and the gas should be at least $1 \mathrm{~K}$ for methane with a concentration of $0.1 \%, 0.4 \mathrm{~K}$ for a concentration of $0.5 \%, 0.3 \mathrm{~K}$ for a concentration of $1 \%$ and $0.2 \mathrm{~K}$ for a concentration of $5 \%$ [Gittins et al. 2001]. On the grounds of the presented results obtained from the performed calculations, it is possible to establish what concentration of gas will be detected by the thermovision camera

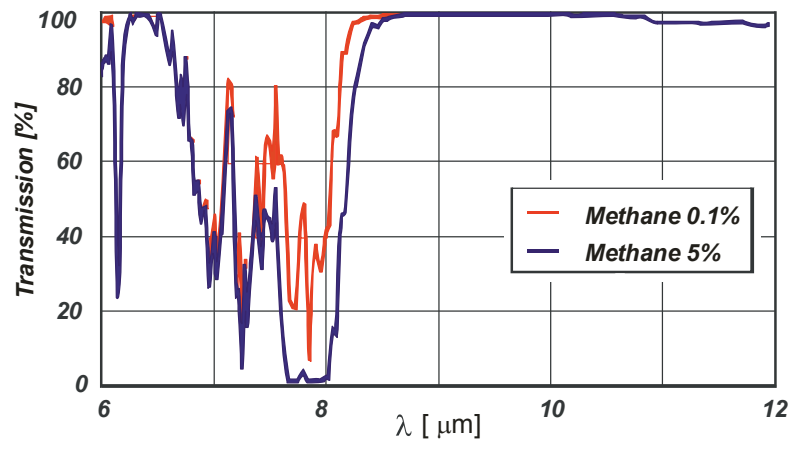

Figure 2. Methane absorption bands in multispectral infrared range for two concentration values.

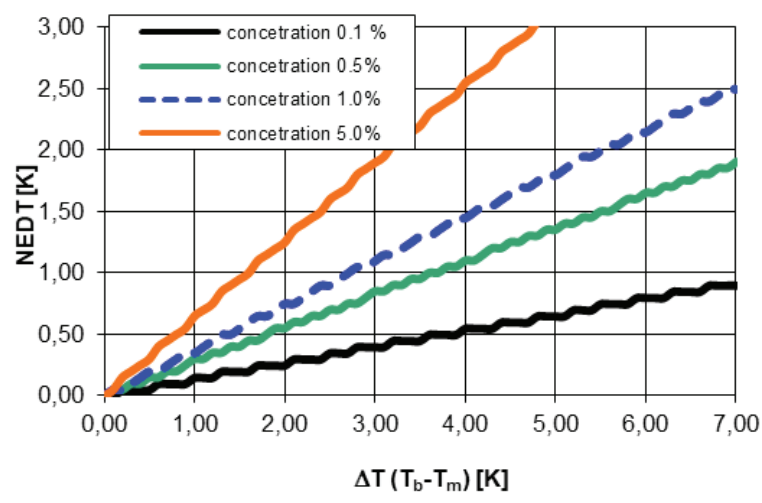

Figure 3. The required difference in the temperature between the background (object) and the gas in the NETD camera function for different values of methane concentration.

with an NETD for a given temperature contrast between the background and the cloud of gas.

\section{SELECTED DEVICES FOR IMAGE DETECTION OF GASES}

First devices used for passive detection of chemical contamination were based on optical filters, in which the spectral features were adapted to the absorption (emission) bands of infrared radiation by vapours of a chemical compound. A few optical filters that had 
spectral features adjusted to the spectral absorption of different chemical compounds were used together with a single filter that had spectral features outside the infrared radiation absorption (emission) bands of the detected chemical compounds. The thermal image registered outside the absorption bands is the image of reference.

Thermovision cameras for the detection of volatile chemicals are equipped with optical systems that ensure appropriate spectral resolution. This is associated with the need to use filters (they are usually tuneable, which enhances the versatility of the device), analysis and information processing systems as well as specific optical systems.

An example of a thermovision camera for the detection of gases is shown in Fig. 4. The system works in the following way: the camera equipped with a filter adjusted to gas absorption bands records (owing to the Cassegrain telescope) two images, A and B.

Radiation registered as image $B$ is additionally passed through a chamber filled with the detected gas. The chamber acts as an additional selective filter. Moreover, the calibration image $\mathrm{E}=$ $\mathrm{A}_{0} / \mathrm{B}_{0}$ that contains information about the asymmetry of the two optical channels is recorded.

Images $A$ and $B$ are applied on top of each other and a resulting correlation image $G=A / B / E$ is indicated. The image that shows the area where the gas is present in the observed scenery is then imposed on the image from the charge-coupled device camera after noise reduction.

The result of these operations is presented in Fig. 4 [Sandsten et al. 2000]. Image (1) shows the leakage of ammonia. Filling the gas chamber with methane enables the detection and visualisation of the cloud of methane, which is shown in image 2 of Fig. 4.

The Flir Systems company produces thermovision cameras for the detection of gases known under the name of GasFindIR (Fig. 5). These are devices dedicated to searching for leakages in gas transmission installations (e.g. in petrochemical plants). GasFindIR operates with a set of optical filters having spectral features adjusted to infrared radiation absorption bands of selected gases.

The device is produced in two versions dedicated to the detection of different gases - GasFindIR SW(operational spectral range is $3-5 \mu \mathrm{m}$ ) and GasFindIR LW (operational spectral range is $8-12 \mu \mathrm{m}$ ). Each of the devices detects approximately 20 kinds of gases. The devices present the cloud of gas in a different colour (Fig. 5). The disadvantage of these devices is that there is no identification of the gas, whilst the advantage is that the device is light and simple to operate.

Other devices use tuneable optical filters that ensure a high spectral resolution. These devices are based on the Fabry-Perot interferometers for an infrared range (Fig. 6). The interferometer module with a thermovision camera was developed by Physical Sciences, Inc. and is available under the name AIRIS (adaptive infrared imaging spectroradiometer). The use of the AIRIS for the detection of gases was tested in many military practice areas and urban conditions [Gittins et al. 2001].

The obtained results confirmed the effectiveness of this type of devices for the detection of chemical contamination. The interferometer plays the role of a tuneable optical filter and decides about the length of infrared radiation waves reaching the

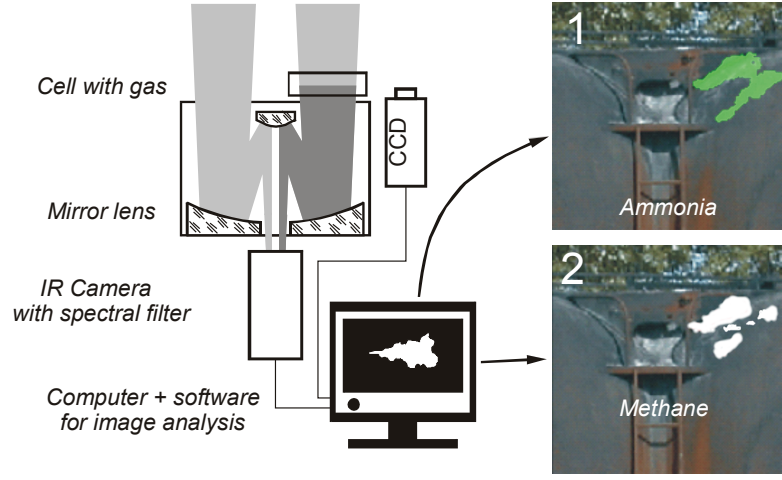

Figure 4. Gas detection system with a thermovision camera.

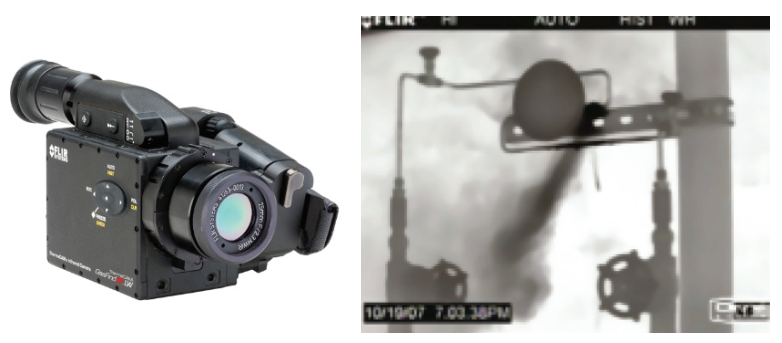

Figure 5. The GasFindIR camera showing the leakage of methane in the transmission installation.

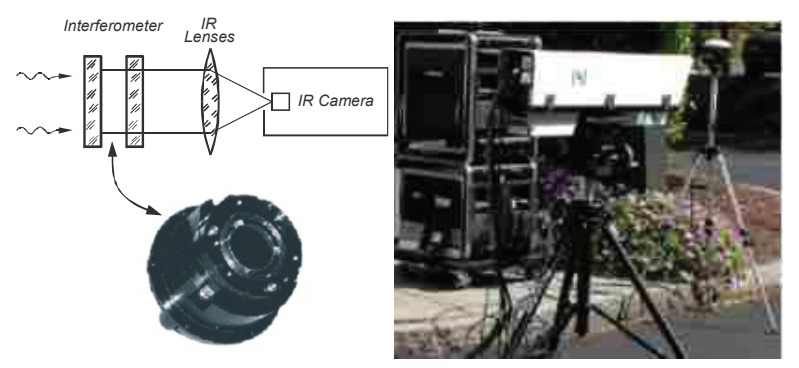

Figure 6. The diagram and the device for contamination detection with an AIRIS system [Marinelli et al. 2005].

thermovision cameras. The operational range of the interferometer fits within the range of 3-5 $\mu \mathrm{m}$ (AIRIS MW) or 8-12 $\mu \mathrm{m}$ (AIRIS LW) (Fig. 6); the tuning speed is 10-20 ms, whilst the precision of tuning to the selected spectral range is $\sim 1 \mathrm{~cm}^{-1}$. The AIRIS module with a long-wave thermovision camera (matrix of detectors $256 \times$ $256 \mathrm{HgCdTe}$ type) was placed on a UH helicopter (Fig. 7) and the effectiveness of chemical contamination detection in urban areas was checked (Fig. 8)

In another device, the AIRIS system was used as a wide area detector (AIRIS-WAD) for chemical contamination detection (Fig. 9). The system enables the detection of a contamination cloud in a $360^{\circ}$ horizontal angle and a $60^{\circ}$ vertical angle, its sensitivity is $1 \mu \mathrm{W} /\left(\mathrm{cm}^{2} \mathrm{sr} \mu \mathrm{m}\right)$, and the parameters of the lens enable the detection of a contamination having a concentration of $100 \mathrm{ppm}$ from a distance of more than $1 \mathrm{~km}$.

The Fourier spectroradiometers, similar to thermovision cameras, 


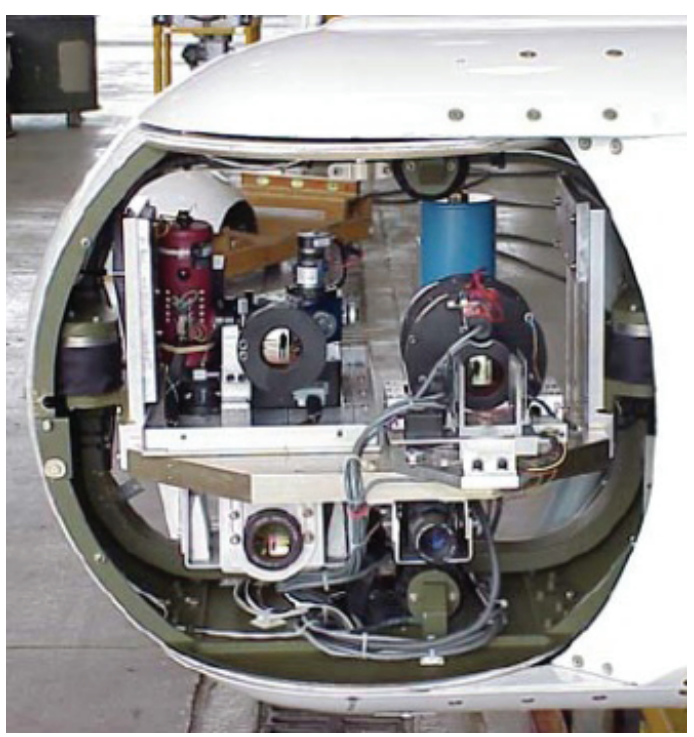

Figure 7. A FAT BOY device with the AIRIS-LW system mounted on a UH helicopter.

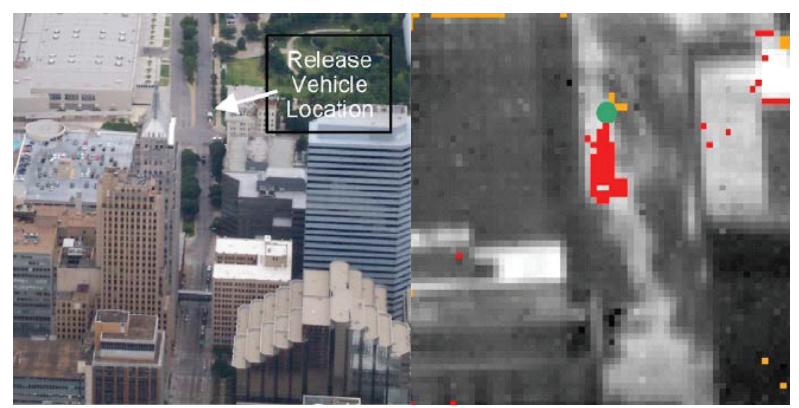

Figure 8. A truck with a leakage simulating a chemical contamination, the image of the detected chemical $\left(\mathrm{SF}_{6}\right)[$ Marinelli et al. 2005].

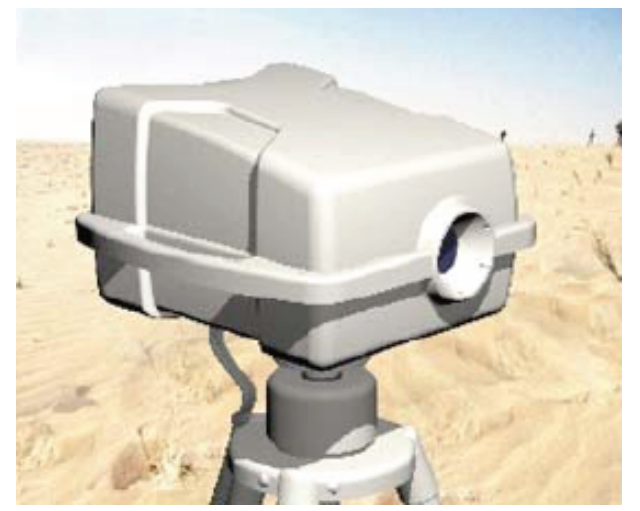

Figure 9. The AIRIS WAD contamination detection system [Marinelli et al. 2005].

make it possible to obtain an image of the thermal scene with an indication of areas where the chemicals to be detected are present. In this case, however, the full spectrum is analysed within the operational range of the device.

An example of a Fourier-transform spectroradiometer Hyper-Cam is shown in Fig. 10. The spectroradiometer is produced in two

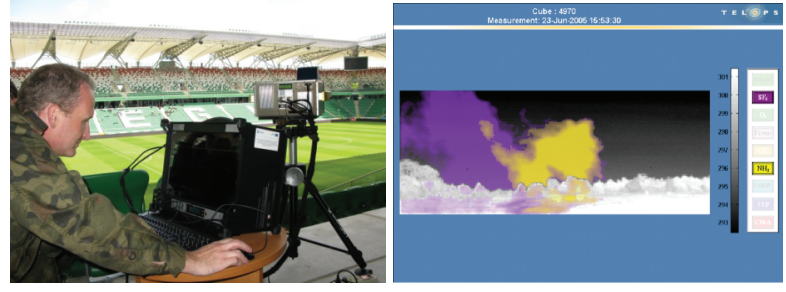

Figure 10. Hyper-Cam spectroradiometer during practice prior to Euro 2012, recording a cloud contaminated by $\mathrm{NH}_{3}$ and $\mathrm{SF}_{6}$ performed by a Hyper-Cam spectroradiometer [Vallières et al. 2005].

versions, depending on its operational spectral range: FIRST MW range 3-5 $\mu \mathrm{m}$ and FIRST LW range 8-12 $\mu \mathrm{m}$. Technical parameters of the device are spectral resolution is from 0.25 to 150 $\mathrm{cm}^{-1}$ (selected by the operator as required) and sensitivity is $2 \mu \mathrm{W} /$ $\left(\mathrm{cm}^{2} \mathrm{sr} \mu \mathrm{m}\right)$; the possibility to continuously register the obtained interferograms gives the device a wide range of applications as a chemical warfare agent (CWA), which gives an early warning about chemical contamination [Vallières et al. 2005].

\section{HYPER-CAM SPECTRORADIOMETER TEST RESULTS}

The infrared IFTS Hyper-Cam uses a Michelson interferometer. The optical scheme with elements changing the optic pathway is depicted in Fig. 11.

Retroreflectors were used instead of mirrors. Owing to that, the movement of the mirror $\mathrm{M}_{2}$ and maintaining the position of the reflecting surface about the optical axis is simpler. It should be noted that the interferometer in the infrared range for radiation having wavelength up to $14 \mu \mathrm{m}$, that is, the realisation of the difference in pathways having large values, requires significant shifts.

The movement of plane mirrors used in a traditional system may lead to misalignment of the reflecting surface. This is a significant source of measurement errors. The arrangement of the movement as shown in Fig. 11 minimises the errors. The fundamental feature distinguishing it from atypical interferometer is the focal plane arrays (FPA). The use of such a detector results in the multiplication of the interferometer for each individual element of the FPA. And so the analysis of interferograms for individual detectors in effect gives an analysis of the entire image.

The analysis of radiation reaching such a detector is identical for all elements. Thus the change in radiation amplitude in the function of optical pathways difference for wavelength $\lambda_{i}$ and the $x$ difference in optical pathways is described in the following:

$A(x)=A_{i} \cos \left(2 \pi \frac{x}{\lambda_{i}}\right)$

The response of the detectors is proportional to the radiation:

$I(t)=I_{i} \cos ^{2}\left(2 \pi \frac{x}{\lambda_{i}}\right)$

After taking into account the dependency on the cosine of the doubled angle, and considering, in further analysis, only 


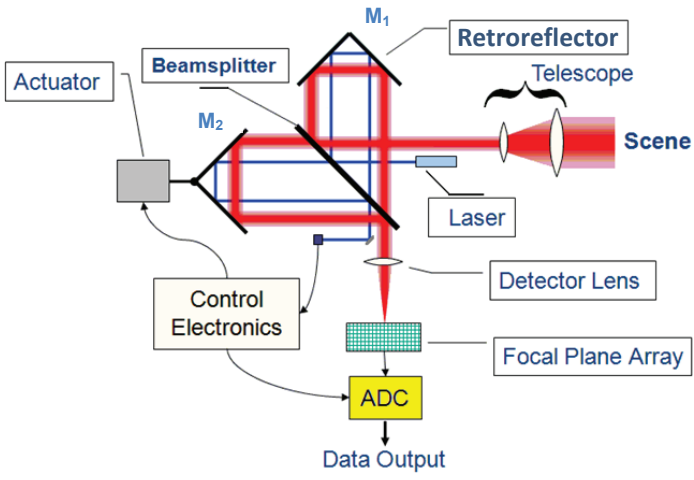

Figure 11. Optical scheme of a Fourier spectroradiometer [Kastek et al. 2011b].

the varying component connected with the change in optical pathways, the changes in radiation in the interferogram are described by the following relation:

$I(x)=I_{i} \cos \left(4 \pi \frac{x}{\lambda_{i}}\right)$.

For the source of continuous radiation in the wavelength range from $\lambda_{1}$ to $\lambda_{2}$, whose spectral distribution is described by the function $S(\lambda)$, the changes in radiation are given by the relation:

$I(x)=\int_{\lambda_{1}}^{\lambda_{2}} S(\lambda) \cos \left(4 \pi \frac{x}{\lambda}\right) d \lambda$.

A typical interferogram curve shows the intensity of infrared radiation in the function of difference in optical pathways realised by the movement of the $\mathrm{M}_{2}$ mirror in the interferometer. For a zero difference in the optical pathways, there is a maximum signal.

The spectral distribution for a given detector can be reproduced by performing an inverse Fourier transform by calculation of the integral:

$S(\lambda)=\int_{-\infty}^{+\infty} I(x) \cos \left(4 \pi \frac{x}{\lambda}\right) d x$.

In practice, the change in difference in optical pathways is realised by a finite, symmetrical range $\pm d$, that is, the integral from relation (11), and will take the form

$S(\lambda)=\int_{-d}^{+d} I(x) \cos \left(4 \pi \frac{x}{\lambda}\right) d x$.

Performing an analysis according to dependency (12) for all elements of the FPA gives a spectral distribution of the entire image. The obtained data forms a three-dimension space, two dimensions are associated with the (2D) image and the third is the wavelength.

The application of specialist methods of analysis of registered data by the image spectroradiometer facilitates the detection of threats from chemical contamination even in cases of automatic detection. Most of the algorithms used in such applications may be categorised according to the operations they perform: (a) finding pixels in a datacube that has a specific spectral signature (detection of aims or anomalies), (b) detecting differences relevant from the user's point of view in the registered data regarding the same area (detection of changes), (c) assigning a particular label to each pixel in the datacube (classification) and (d) estimating the substance content in the image depicted by a single pixel (decomposition). With respect to the signal processing, operation (c) is a matter of classification, whilst operation (d) is a matter of estimation [Kastek et al. 2011a].

The target detection and identification algorithm is generally based on three key factors: the composition of the analysed pixel, the type of model used to estimate the variability of the target and background spaces and the model used to describe the pure and mixed pixels. The mathematical representation of a mixed pixel depends on whether the background (or target) space is estimated statistically or geometrically. The considered sub-pixel target detection algorithms are of a stochastic nature. When the background is entirely represented by its statistics, the detection problem consists in extracting the targeted spectral signatures from a background noise term, $\varepsilon_{b}$. Equations (8) and (9) express this symbolically:

$H_{0}: x=\varepsilon_{b}$

$H_{1}: x=T_{a}+\varepsilon_{b}$

Here, $a$ is the weighting vector to be estimated and $T$ is the matrix of ' $k$ ' targets: $\left[t_{1}, t_{2}, t_{3}, \ldots, t_{k}\right]$. It is assumed that the noise component has a mean value of zero and covariance $C$.

The basic idea behind the clutter-matched filter (CMF) is to minimise the response to the unknown background signatures whilst accentuating the response to the target spectrum. To do so, the following mathematical operation was developed:

$q_{i}=\frac{C^{-1} t_{i}}{\sqrt{t_{i}^{\prime} C^{-1} t_{i}}}(15)$

where $q_{i}$ is the CMF related to the ith target $t_{i}$ taken from the matrix of targets $T$ and the $\mathrm{N} \times \mathrm{N}$ estimated covariance matrix, $C$, is given by equation (16):

$C=\frac{1}{(M-1)} \sum_{i=1}^{M}\left(x_{i}-\mu\right)\left(x_{i}-\mu\right)^{\prime}$

Here, $x_{i}$ and $\mu$ are, respectively, the spectrum of the ith pixel and the mean pixel of the scene and $M$ is the number of pixels from the image used to estimate the covariance. This model falls under the stochastic methods category.

The signal-to-clutter ratio is simply calculated with equation (17):

$\frac{\text { Signal }}{\text { Clutter }}=q \cdot\left(x_{i}-\mu\right)$

If the CMF is not calculated for each scene, which is sensible if real-time processing is required, then the mean pixel found in equation (16) must be the one introduced in equation (17) when the covariance matrix was introduced.

The CMF is normalised so that when the signal is absent, the probability density function of the filtered image has a standard 
deviation of 1 . The score of each pixel denotes the number of standard deviations that this pixel parts from zero. As can be ascertained with equation (15), the response of the CMF is linearly dependent on the target signature. The results obtained with this model give an approximate concentration of the targeted species occupying the pixels. Effectively, the scores obtained when the CMF is applied are a good indicator of the strength of the signal, which, in turn, is proportional to the temperature contrast and to the column density of the target.

When the target mean is known, it is possible to use the spectral angle mapper (SAM or, as it will sometimes be called in this article, the correlation coefficient) to detect the presence of targeted species. As its name indicates, SAM is an algorithm that computes the angle formed by the projection of a target on an image pixel:

$x_{i} \cdot t=\left\|x_{i}\right\| t_{i} \| \cos (\theta)$

or, in a more common form,

$\cos (\theta)=\frac{x_{i} \cdot t}{\left\|x_{i}\right\| t \mid t}$

The results are limited between 0 and 1 . A value of 0 signifies that the image pixel and the target are not at all correlated, whereas a score of 1 means that the two vectors are perfectly correlated. SAM is obviously not a linear filter, and it cannot indicate the strength of the signal. The detection and identification of chemical agent is performed through post-processing of the recorded hyperspectral data. The algorithm integrates a double-stage decisional scheme that is used to analyse the hyperspectral data produced by Hyper-Cam sensor. Measurement of the background is performed to obtain the covariance matrix of the scene. This covariance is used to calculate the CMFs for several gas signatures from a library based on The Pacific Northwest National Laboratory [PNNL] data. On each scene measurement, the background is removed and the calculation of the image of CMF scores and correlation (SAM) scores is performed. To detect and identify a given chemical agent, the score from both calculations (CMF and SAM) must exceed a given threshold [Chamberland et al. 2014].

Figure 12 shows a simplified diagram of a processing chain of spectral data, starting from a calibrated datacube and involving common elements, such as compensation of the atmosphere impact and dimensionality reduction. Further specialist procedures in data processing depend on a particular application.

The aim of such a detection algorithm is to develop a map of objects with a constant false-alarm rate (CFAR). This is a desired feature in algorithms of this type. Change detection algorithms generate maps of significant changes in the observed scene, which, in order to be credible, operate based on the credible threshold of CFAR changes. Rigid or flexible thematic maps generated by the above CFAR algorithms carry information about the substances in the observed scene and the information may be more efficiently exploited for the detection of objects or changes. The method that uses thematic maps cannot be used

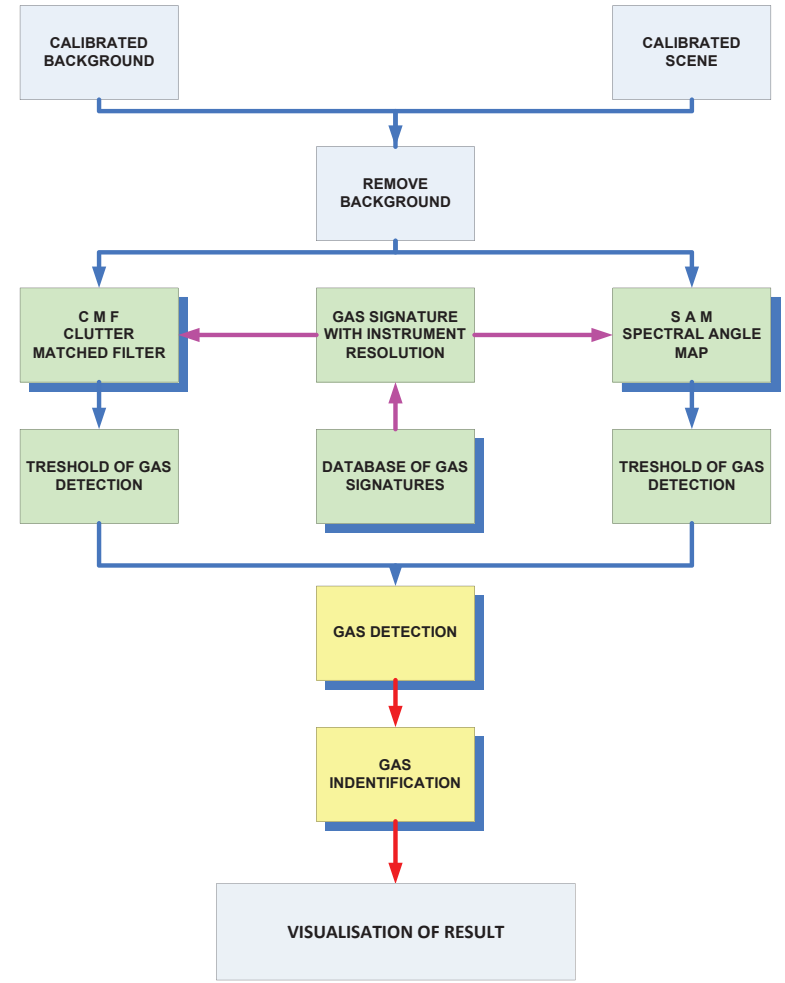

Figure 12. Flow chart of spectral data processing.

for the detection of targets because of the absence of training data for given targets. Detection and classification look almost identical. However, the two differ significantly in both theory and practice because of the uniqueness of aims, the final effect (maps of object detection - thematic maps) and different cost functions (errors in pixel classification on the thematic map are not as critical as the omission of the object or the overloading of the algorithm for tracking the object with false alarms).

In course of laboratory and polygon tests performed with the Hyper-Cam spectroradiometer, the possibility of detection of $\mathrm{CO}_{2}$, a mixture of propane and butane and Freon $134\left(\mathrm{CH}_{2} \mathrm{FCF}_{3}\right)$ was examined. The trials were carried out in different atmospheric conditions and with different concentrations of the gases. Freon 134 was detected during polygon tests using the Hyper-Cam LWIR by placing a gas cylinder at a distance of 20 and $60 \mathrm{~m}$ with a controllable valve [Chamberland et al. 2014].

Aconcentration of $3 \%$ and $6 \%$ was obtained through the controllable valve. Atmospheric conditions were monitored when the gas flowed out of the pipe by a weather station, recording the direction, wind strength, temperature and air humidity. The analysis of the measurement conditions made it possible to determine the value of the temperature contrast between the gas and the background; it was found to be $3^{\circ} \mathrm{C}$. Figure 13 depicts the obtained results of the data registered with a spectroradiometer and the results obtained with the above-described method in MATLAB.

\section{SUMMARY}

Infrared devices that are used for the detection of chemical contamination belong to the currently developed group of early 
(a)
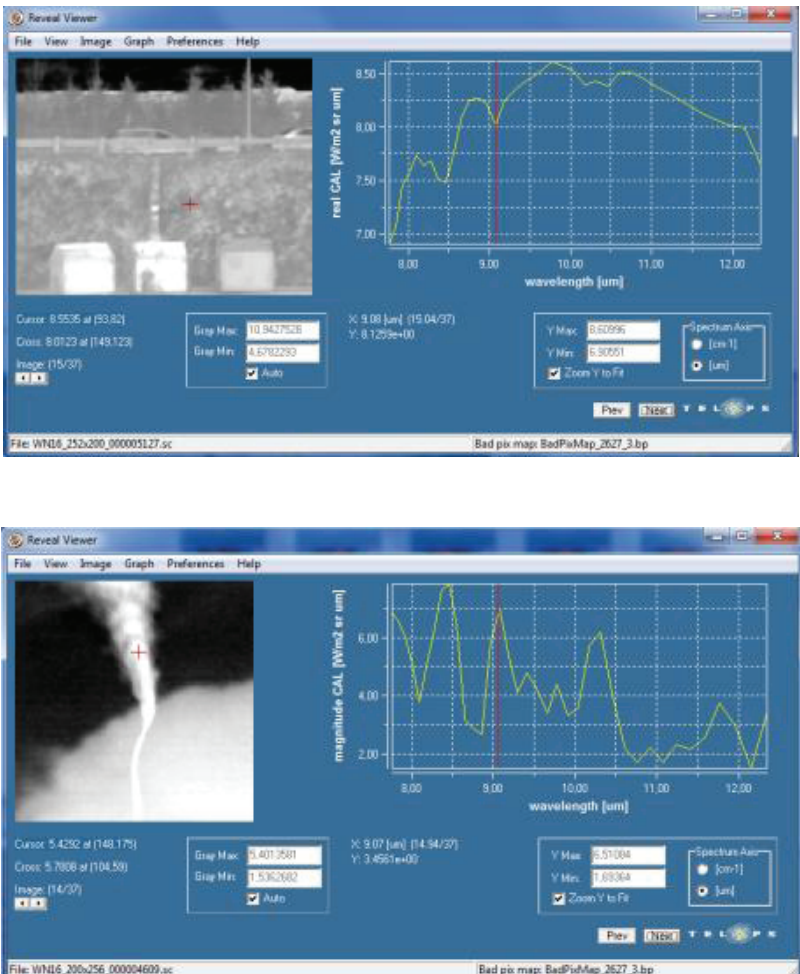
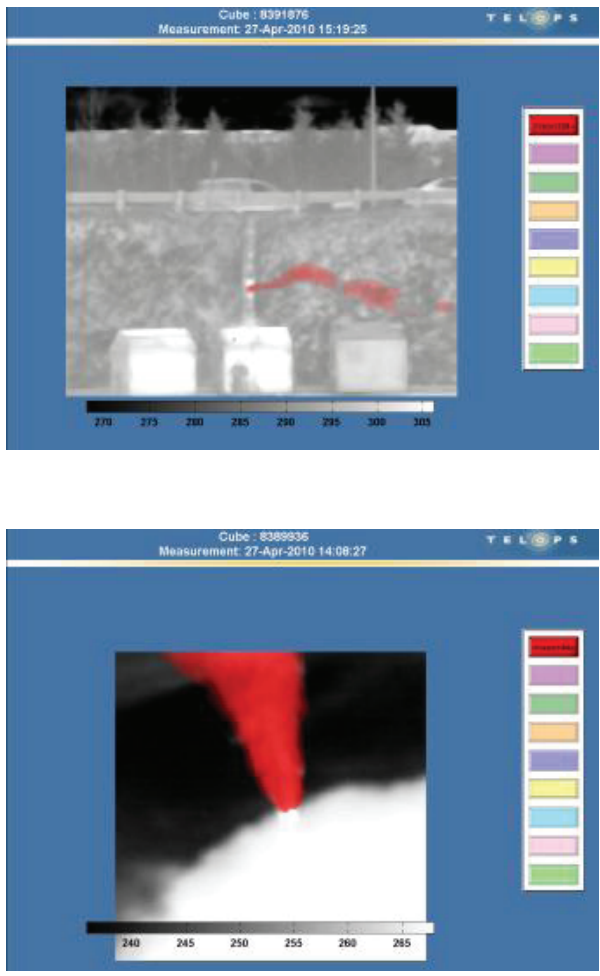

Figure 13. The test results for the detection of Feron 134 (concentration $3 \%, T_{\text {atm }}=18{ }^{\circ} \mathrm{C}, v_{\text {wind }}=8 \mathrm{~m} \mathrm{~s}^{-1}, p_{\text {atm }}=992 \mathrm{hPa}$ ) placed at a distance of (a) $20 \mathrm{~m}$ and (b) $60 \mathrm{~m}$.

warning about chemical contamination devices. The distance of contamination detection largely depends on the sensitivity of infrared plane array detectors and the optical systems used.

Owing to the initial research on Fourier image spectroradiometers, it may be concluded that only experienced specialists with in-depth knowledge and expertise are able to detect the contamination and state precisely what type of gas was the cause, whereas the use of modern data processing methods facilitates the automatic detection and identification of chemical contamination based on the reference spectral characteristics of chemical gases.

\section{REFERENCES}

GITTINS M., MARINELLI W. J. AND JENSEN J. O. 2001. Remote Sensing and Selective Detection of Chemical Vapor Plumes by LWIR Imaging Fabry-Perot Spectrometry, Proc. SPIE 4574, pp. 63-71.

KASTEK M., PIĄTKOWSKI T., DULSKI R., CHAMBERLAND M., LAGUEUX P., FARLEYV. 2012a.Hyperspectral Imaging Infrared Sensor Used for Chemical Agent Detection and Identification, Symposium Photonics and Optoelectronics (SOPO), Conference Guide, art. no. 6270545.

KASTEK M., PIĄTKOWSKI T., DULSKI R., CHAMBERLAND M., LAGUEUX P., FARLEYV. 2012b. Method of gas detection applied to an infrared hyperspectral sensor, Photonics Letter of Poland, vol. 4 (4) pp. 146-148.
Specialist methods of analysis based on CMF and SAM, in addition, facilitate the assessment of the size of the chemical substance leakage. Research is currently in progress, and initial results have already been presented at international conferences [Kastek et al. 2012a, 2012b].

Increased sensitivity of infrared plane array detectors dedicated to the stand-off passive detection of chemical contamination will make it possible to expand the detection ranges as well as facilitate the detection of smaller concentrations of chemical contamination.

KASTEK M., PIĄTKOWSKI T., POLAKOWSKI H. AND SOSNOWSKI T. 2008. Methane detection in far infrared using multispectral IR camera, 9th International Conference on Quantitative InfraRed Thermography, Kraków, pp 347-350.

KASTEK M., PIĄTKOWSKI T., POLAKOWSKI H. 2011a. Infrared imaging Fourier-transform spectrometer used for standoff gas detection, 19th International Conference on Modelling, Monitoring and Management of Air Pollution, WITPress, Southampton, Boston, UK, pp. 161-172.

KASTEK M., PIĄTKOWSKI T., TRZASKAWKA P. 2011b. Infrared imaging Fourier transform spectrometer as the stand-off gas detection systems, Metrology and Measurement Systems, Vol. XVIII, No. 4, pp. 607-620. 
LAVOIE H., PUCKRIN E., THÉRIAULT J. M. AND DUBÉ D. 2007. Measurement of toxic industrial chemicals, chemical warfare agents and their simulants. A LWIR passive standoff detection study, Defence R\&D Canada - Valcartier Technical Report, DRDCValcartier TR 2006-634.

MARINELLI W. J., GITTINS C. M., COSOFRET B. C., USTUN T. E. AND JENSEN J. O. 2005. Development of the AIRIS-WAD Multispectral Sensor for Airborne Standoff Chemical Agent and Toxic Industrial Chemical Detection, presented at Parallel Meetings of the MSS Specialty Groups on Passive Sensors; Camouflage, Concealment, and Deception; Detectors; and Materials (Charleston, SC).

SANDSTEN J., WEIBRING P., EDNER H. AND SVANBERG S. 2000. Real-time gas-correlation imaging employing thermal background radiation, Optics Express 92, Vol. 6, No. 4.

VALLIĖRES A., CHAMBERLAND M., FARLEY V., BELHUMEUR L., VILLEMAIRE A., GIROUX J. AND LEGAULT J. F. 2005. High-performance field-portable imaging radiometric spectrometer technology for chemical agent detection, Proc. SPIE 5590.

CHAMBERLAND, M., LAGUEUX, P., TREMBLAY, P., SAVARY, S., GAGNON, M.-A., KASTEK, M., PIATKOWSKI, T., DULSKI, R. 2014.Standoff gas detection, identification and quantification with a thermal hyperspectral imager, WIT Transactions on Ecology and the Environment, Volume 181, Pages 671-682. 